\title{
Aspects of Decision-Making System Development During Enrollment Campaign in Higher Education Institutions \\ ${ }^{* 1}$ E.N. Novikova, ${ }^{2}$ R.M. Akhmetshin, ${ }^{3}$ O.V. Martynova \\ 1, 2,3 Kazan Federal University
}

Received: 15th December 2017, Accepted: 20th December 2017, Published: 31st December 2017

\begin{abstract}
The study explores the aspects of decision making system development within enrolment campaign in institutes of higher education. Based on the survey on entrants' and students' opinion main directions are assumed for the creation of integrated communication system involving existing and potential consumers of educational services, as well as university's image development. Creation of professional laboratories within programs of specialization. The creation of professional practical field for students, bachelors, masters, postgraduate students and lecturers within the university.
\end{abstract}

Keywords: Enrolment Campaign, Integrated Communications System, Practice-Oriented Education, Industry Related Education,

\section{Introduction}

Under rather severe competition in the educational services market, Management and staff of institutes of higher education have to develop and introduce measures of rising the level of self-competitiveness. Following the initiation of the guidelines on assessment the institutes of higher education by the Ministry of education and science of the Russian Federation, it becomes necessary to consider optimization measures for entrants' attraction, that affect academies performance both in short-term and long-term perspectives.

Consequences of the demographic crisis of the end of 90s have resulted in the objective reduction of students' number and failure to meet the required level of enrolment on commercial basis on different programs.

New environment demands the necessity for education relations management, based on initiative activity of educational organizations - educational entrepreneurship. The issues of entrepreneurship development are covered in works by Kalenskaya N.V., Akhmetshin R.M., Grigoryeva L.L., Shafigullina A.V. [1], [3], [9].

In order to come up with optimal management solutions providing balance between entrants', employers' and academies' interests, the development of a new decision making system is expected under enrolment campaign management, based on integrated communications system application, active forming of positive students' opinion about the Institute of management, economics and finance of Kazan Federal University, as well as clear outlining the benefits, offered by the University.

In this environment the proposed decision making system within enrolment campaign management in institutes of higher education will let increase the quality of enrolment campaign, find efficient management solutions both for academies and employers and for students that finally will affect the efficiency and competitiveness of the University.

\section{Method}

To solve the problem of insufficient number of entrants' enrolment in the Institute of management, economics and finance, a survey and a focus-group were held among first-year students studying "Economics" and "Management" on a commercial basis. The survey included 143 students. 70 students, studying "Economics", and 73 students, studying "Management". The questionnaire is presented in the Annex 1.

The distribution of respondents by age and sex is the following: at the age of 17 years $-12.6 \%, 18$ years $77.6 \%, 19$ years $-9.8 \% .22 .4 \%$ of respondents were represented by men and $77.6 \%$ by women. $10 \%$ of the respondents are married.

$67.8 \%$ of respondents are citizens of the Russian Federation, $4.2 \%$ - are from foreign countries, $28 \%$ students from rural areas. The average academic score of the entrants of the Institute of management, economics and finance is above 4 . Most of the respondents - $65 \%$ - are high school graduates, $16.8 \%$ - gymnasium graduates, $18.2 \%$ - lycee graduates.

The distribution of the average per capita income in entrants' families is the following: $7.5 \%$ - income less than 4000 rubles per person, $22 \%$ of the respondents have more than 10000 rubles per person, $53 \%$ of respondents have 4000 to 10000 rubles per person, the rest have found it difficult to answer.

$5 \%$ of the respondents have known about the chosen program from media, more than $90 \%$ - from their friends and relatives, one respondent has known from his parents.

The question regarding students' opinion about the chosen university divided the answers into two: one part was "generally positive opinion" and the other was "both positive and negative".

The question about the information required for an entrant to make a decision before applying to a 
university, was difficult to answer for most of the respondents, argumenting to an information provided by selection committee, nevertheless, some of the respondents would like to get the requested information before application (the answers either are expected too long/ or the information is used to be sent after the application and the entrants have to use the information from other students or relatives). Among the main factors affecting the choice of the university entrants were mentioned the following (fig. 1):

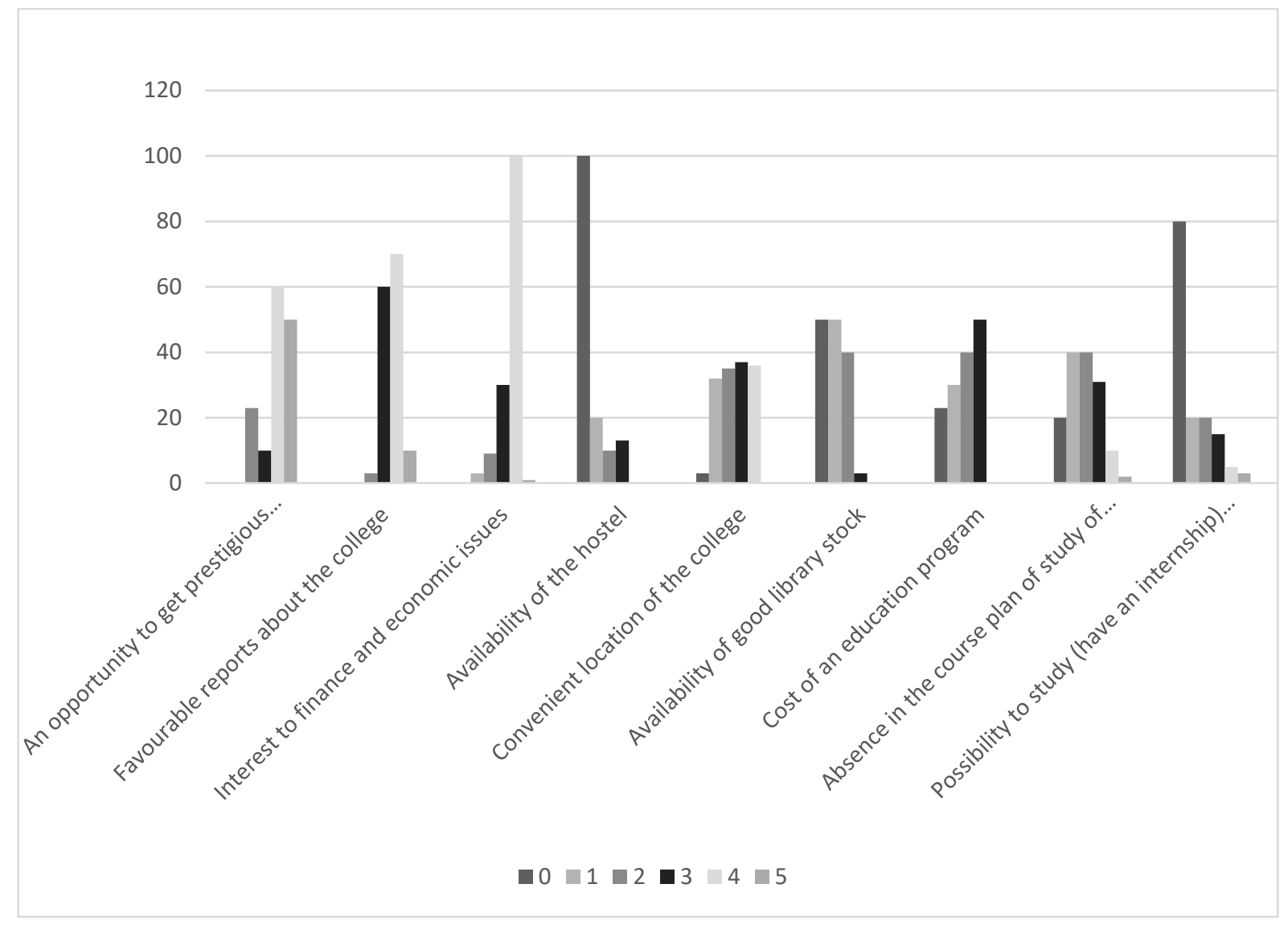

Fig. 1. Factors Influencing the Choice of Entrants to an Institute of Higher Education.

1. An opportunity to get prestigious appointment in a job

2. Favourable reports

3. Interest to finance / convenient location of the university

Among the institutes of higher education, situated in Kazan and competing for the entrants with the Institute of management, economics and finance, are Kazan National Research Technical University, Kazan National Research Technological University, and Law faculty of Kazan Federal University. Among the main competitors in other cities are State University of Management (Moscow), Higher School of Economics (Moscow), Financial academy
(Saint-Petersburg), Bashkir State University (Ufa), Branch of Kazan Federal University in Naberezhnye Chelny.

All students are quite optimistic about their salary in future, though they are not sure whether they are going to stay in Kazan after graduation from the university.

$70 \%$ of the respondents answered that they are interested in information about the possibilities of job placement in chosen specialty, and consider important to work together with potential employers during the process of getting educational services through arranging meetings and talks with representatives, as well as creating laboratories or participation in joint projects (fig. 2). 


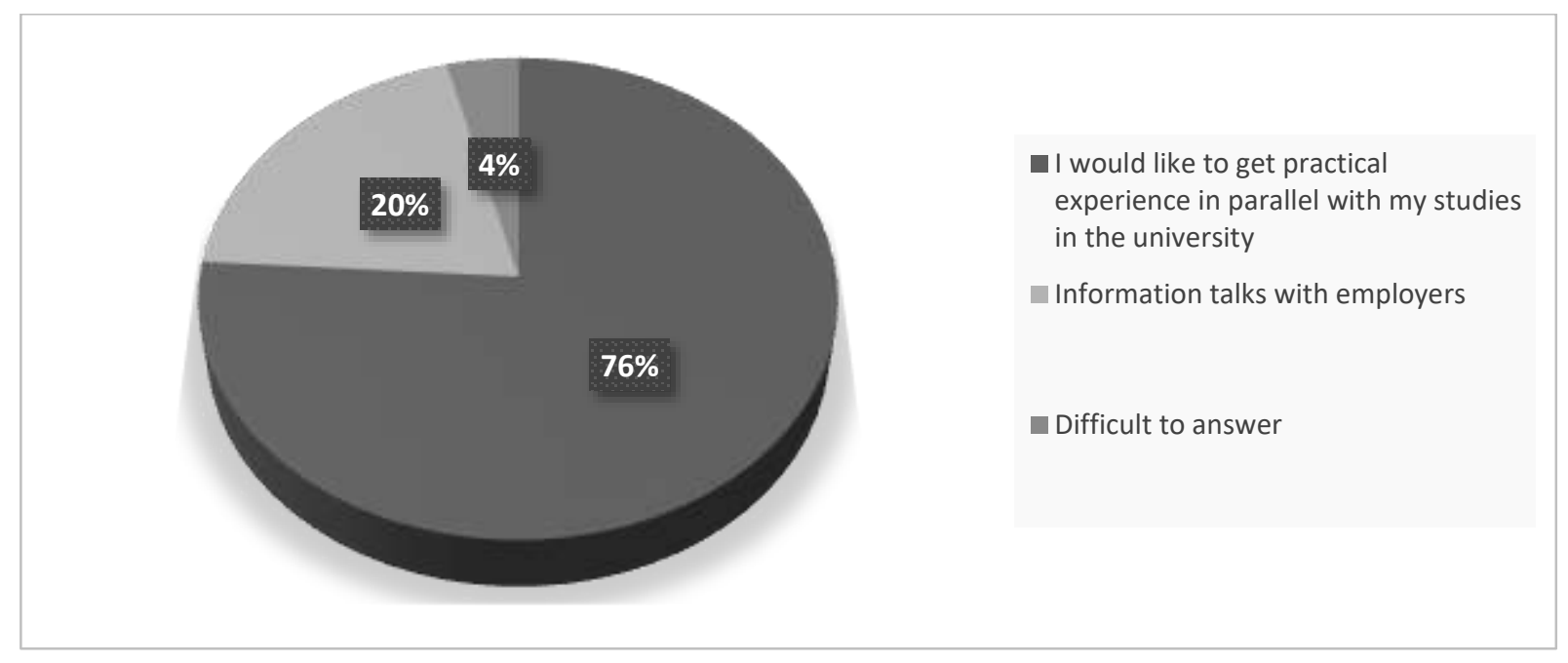

Fig. 2. Interest to Future Job and Possibilities of Job Placement

Around $20 \%$ would be satisfied enough only by information talks with employers, the rest have found it difficult to answer. Nevertheless, almost everyone was interested in obtaining the information by the moment of their graduation about available vacancies in organizations - partners of KFU.

Creation of professional laboratories within programs of specialization fully complies with interests of the students, facing the necessity to earn a living and education cost $(72.0 \%)$ and interested in postgraduate job placement $(64.0 \%)$. Students would like to work to get professional experience in certain field, prepare a competitive curriculum vitae and increase their chances in getting a desired joboffer. Students' striving to become familiar with different kinds of job during their education in the university is also clear, as it increases their opportunities to choose the most appropriate one in future. $62 \%$ of the respondents feel aspiration to run level with other students, know something new, feel stronger relationship between applied efforts and final result that is quite rare to be proven.

According to the students' opinion, the main aim of the studies is getting knowledge and diploma. These are adequate and traditional answers to the question.

Most of the respondents are satisfied with the education system in the IMEF, thought they would like to have more freedom in decision making and practical application of knowledge they get. Part of the students does not support the rating system.

The answers to the questionnaire have revealed a high potential of IMEF students in business ideas generating, moreover these ideas are related to services industry not only due to the interest, but also because of the possibility to create more benefits at the minimum investments.
These students' ideas are in germ as most of the respondents have no idea how to realize them. It represents mainly the lack of information, financial and legal competence.

Students would like to work on their ideas during the whole process of education and as a result to present the business plan of their project. Most of the students have their own ideas, but need assistance and support. In most cases, this is financial (68\%) and legal (20\%) support. Psychological support - 7\% of the respondents. $36 \%$ of students connect the possibility of business ideas implementation with their study at the university and would like to realize it in academy's laboratory. Among the impediments toward business ideas implementation are lack of trust to the lecturers and other students (the possibility of information leakage), lack of information about the matter and negative attitude to novation in general.

More than $70 \%$ of respondents would like to participate in real projects during their education, given that their efforts within these projects would be paid up. Around $20 \%$ of respondents are ready to work on volunteer basis. The rest found it difficult to answer (fig. 3).

$96 \%$ of the respondents have mentioned that they don't have enough information about contests and industry-related events, while only $4 \%$ have.

\section{Result and Discussion}

The aim of this research is to increase the competitive level of IMEF in the market of commercial educational services through nonfinancial factors, by introduction of integrated system of communications with entrants and students. 


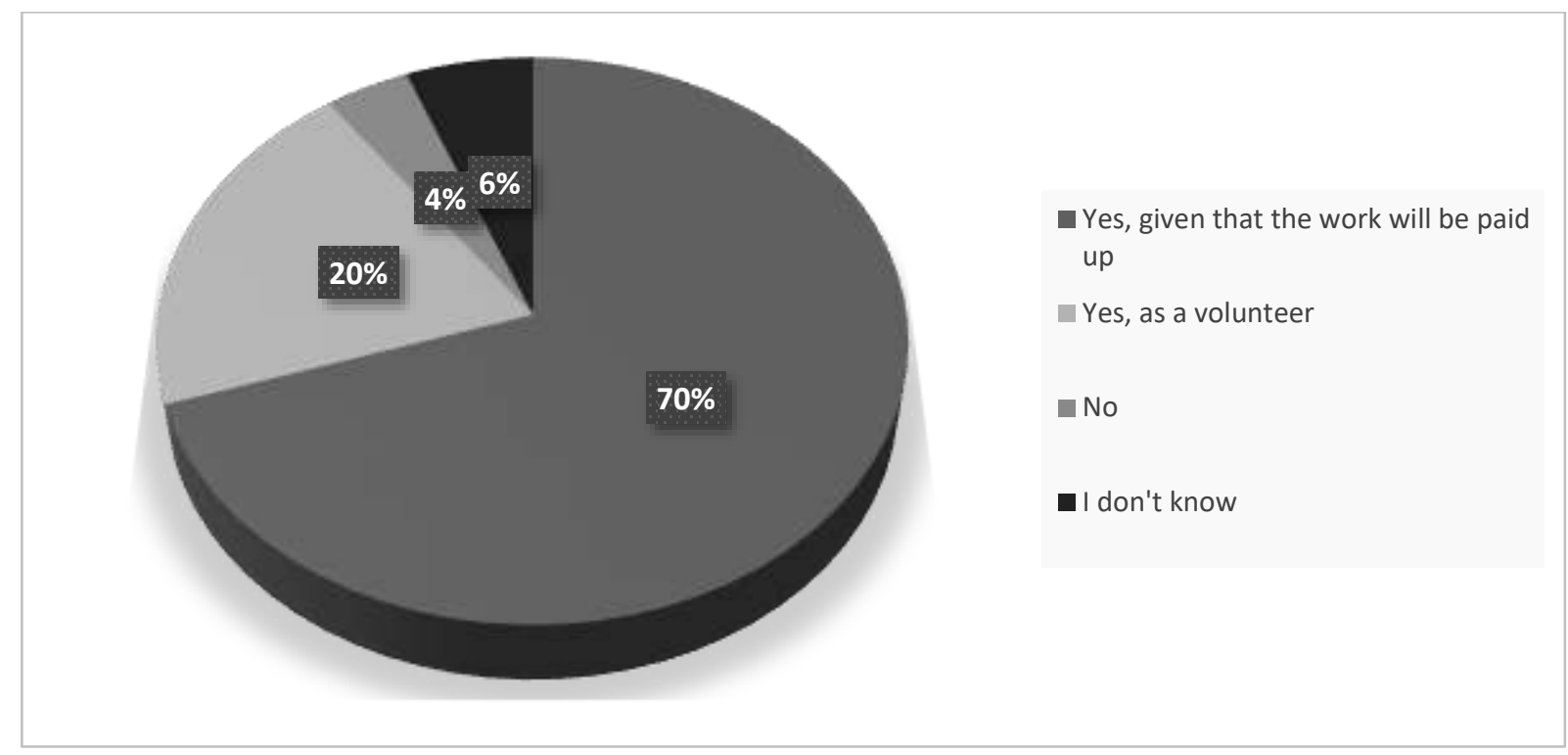

Fig. 3. Willingness to Participate in the Projects of Laboratories

Based on the results of the survey it is necessary to develop a complex system of decision making aimed to inform students and entrants and provide the possibility for practical skills application within laboratories of the university.

The interaction of the laboratory with other subjects of decision making is represented on fig. 4
An information between the subjects of the system should be exchanged on the ground of created marketing information system. The approach offered by Novikova E.N., Beloborodova A.L. in their researches [5], [6] may be accepted as a base.

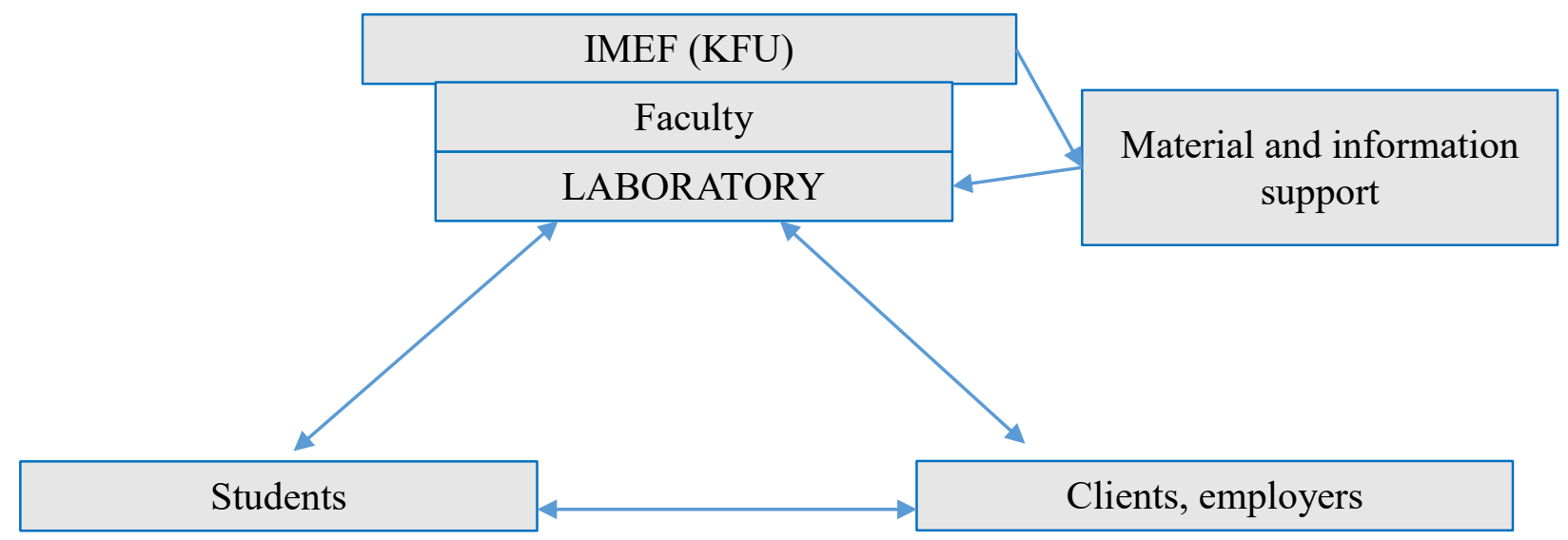

Fig. 4. Interaction between the Subjects of Decision Making System

The place of the laboratory in the management system should be determined with regard to the requirements of quality assurance system of the organization. The issues of quality management are studied in works of Sharafutdinova N., Valeeva J [8]. To provide functioning laboratory needs the following material and information support:

- Premises (around 20 square meters)

- Technical means and equipment (laptop, mouse, mobile loudspeaker, multifunctional device -3 sets)

- Access to the Internet;

- Access to legal databases;

- Software (Corel Drow, SoundForge, MS Office, Photoshop, Acrobat reader, Illustrator)
- Furniture for the meeting room;

- Flip charts, interactive whiteboard;

- Mobile projector;

- Consumables (stationery, water, cartridge, toners)

Organizational and legal requirements for the proposed idea.

It is necessary to develop the rules of a laboratory, covering aims and tasks of a laboratory, its position in the management structure of IMEF. It is also important to determine financial sources of its functioning, as well as set the regulations for contractual work of a laboratory (part of the income 
transferred to the university, compensating students' labor, transactional expenditures, etc).

Under the project implementation is it proposed to organize the following model of laboratory regulation within the faculty. One of the faculty members is assigned as a head of a laboratory, responsible for its functioning under signed agreements, dealing with the management of the institute and the university, signing the list of concordance, coordination of students' work and coordination with student organizations. Head of a laboratory will be also responsible for collaboration with the selection committee to attract entrants to the university, as well as for participation on different exhibitions, fairs, interaction with press office of the university and other media. However, to involve more students to the project activity, to distribute the responsibilities within signed agreements, it is highly recommended to appoint representatives of the client as heads of the projects. That would let to avoid numerous issues related to the problem description, need to be solved under the collaboration with a laboratory, would introduce closer the inner standards of the organization, codes of ethics to the students, at the same time that would let client choose employee based on objective analyses of his activity.

The following measures are recommended under the improvement of communication system within the enrolment campaign:

1. It is necessary to increase the rate of interaction between selection committee members and entrants.

2. Promotion of application through the Internet.

3. It is necessary to work more actively with entrants, to invite them to open house days, interview and allocate the information through all possible channels of communication.

4. Active involvement of student organizations in enrolment process through business games arrangement and cultural work among the masses in the Republic of Tatarstan.

5. To increase the attractiveness of education programs of the IMEF it is recommended:

6. To create student laboratory, aimed to implement economic and marketing projects in collaboration with business organizations (future employers, consulting companies).

7. Section of the KFU web-site devoted to vacancies for graduates has not been updated for a long time, it is necessary to activate its functioning through employers and recruiters' attraction.
8. To increase the promotion through social nets, that would positively impact on the interest to the programs.

9. To create the system informing about future contests, projects, etc, by subscription, SMS and email alerts of the students about upcoming events.

10. To build an online consultant at KFU website, and introduce a call-center consulting on terms and conditions of projects participation.

\section{Conclusion}

Measures mentioned above would contribute to:

1. The creation of professional practical field for students, bachelors, masters, postgraduate students and lecturers within the university.

2. The development and implementation of practical part of education programs on building-up entrepreneurial competences for businesses.

Students might be attracted by following opportunities:

- Learning the specialization in practice;

- Self-affirmation, freedom within scientific work;

- Financial compensation;

- Participation in competitions and grants;

- Job placement after graduation from the university.

\section{Acknowledgements}

The work is performed according to the Russian Government Program of Competitive Growth of Kazan Federal University.

\section{References}

1. Akhmetshin R.M. Shafigullina A.V. Development Trends of Entrepreneurial Activity in the Republic of Tatarstan //Mediterranean Journal of Social Sciences, 6, №1S3, 2015, pp. 495-498

2. Antonchenko N.G., Kalenskaya N.V. Developing a Methodology for Assessing

the Efficacy of Managerial Decisions in Entrepreneurial Establishments. // Life Science Journal, 2014, № 11(7s), pp. 365 - 369.

3. Bagautdinova N.G., Khametova N.G., Svirina A.A. Quantitative assessment of influence of management quality of activity of business firm // World Applied Sciences Journal, 25 (8), 2013, pp. 1145-1149.

4. Beloborodova A.L. An Efficiency Estimation for Activities for Multi-Industry Holdings as Forms of Business Associations // Mediterranean Journal of Social Sciences, 2015, Vol. 6, № 1S3, pp. 491-494. 
5. Kalenskaya N.V., Akhmetshin R.M., Grigoryeva L.L. The Development of State Regulation in Small Entrepreneurship Infrastructure Provision //Mediterranean Journal of Social Sciences, Vol. 18, 2014, pp. 27-33.

6. Martynova O.V., Valeeva Y.S. Development Typology for Retail Networks in the Russian Federation //Mediterranean Journal of Social Sciences, Vol. 6, No 1, Supplement 2, January, 2015, pp.155-159

7. Novikova E.N. Design of a marketing information system //Mediterranean Journal of Social Sciences, Vol 6, No 1 S3, February, 2015, pp.141-145

8. Novikova E., Beloborodova A. An Assessment of the Efficiency of the Information System of Design-and-survey Organizations Based on the
Analysis of the Information Capacity of Projects Implemented// World Applied Sciences Journal, 29 (1), 2014, pp. 20-25,

9. Palyakin R.B., Tarkaeva N.A. The Relationship of Entrepreneurial Activity and the Level of Institutional and Market-Based Infrastructure of Business. // Mediterranean Journal of Social Sciences, №18 (v5), 2014, pp.305-311.

10. Sharafutdinova N., Valeeva J. Quality Management System as a Tool For Intensive Development of Trade Organization //Mediterranean Journal of Social Sciences, 2015, Vol. 6, № 1S3, pp. 498-502.

11. Shafigullina A.V., Akhmetshin R.M. Development trends of entrepreneurial activity in the Republic of Tatarstan // Mediterranean Journal of Social Sciences, 2015, Vol. 6, № 1S3, pp. 495-497. 